\title{
マフノリ粘質物稀薄水溶液の粘度*
}

\author{
圓田雄造・岸本昭 \\ (1962 年 3 月 30 日受理)

\section{VISCOSITIES OF FUNORI EXTRACTIVE IN AQUEOUS POTASSIUM CHLORIDE}

\author{
Yuzo ENDA and Akira Kishimoto**
}

\begin{abstract}
Reduced viscosities of Funori extractive, the water-soluble extractive from the red sea weed Gloiopellis tenax, in aqueous potassium chloride were measured at $30^{\circ} \mathrm{C}$. as a function of Funori concentration $C$ and $\mathrm{KCl}$ concentration $x$. The family of $\eta_{s p} / C$ vs. $C$ curves obtained for different $x$ was essentially similar to that which had been reported for many other polyelectrolytes. From comparison with data for agar-agar some evidence was obtained which indicates the Funori molecule to have a higher charge density than the agar-agar molecule. A parameter, $m$, in the PALS-Hermans method of iso-ionic dilution was found to have a value less than unity, which may be attributed to a binding of counterions to the oppositely charged polyion.
\end{abstract}

フノリ粘質物は寒天と同じように硫酸基，カルボキシル基の二種の笔離基をるつ複雑な高分子塩である。

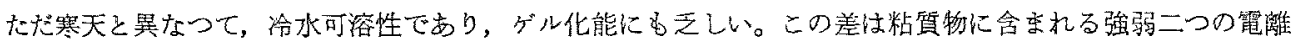

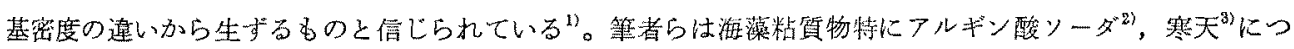
いて一連の粘度剆定を行なつてきた。本論文け前二者と比㜞する目的で, $\mathrm{KCl}$ を添加塩としマフノリ抽出物 について求めたかなり詳細な粘度测定の結果を報告する。

実験

\section{1. 武 料}

市貼朝鮮産マフノ，Gloiopellis tenax を撰別して用いた。風乾した原藻を水道水，蒸溜水で軽く洗つた

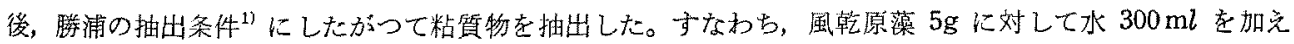
一夜故置後，温浴上で $95^{\circ} \mathrm{C}$ で 2 時間加温する。No.1 のガラスフイルターを通して沪過し，沪液に KCl 水溶液加兄 $95^{\circ} \mathrm{C}$ で 30 分加熱後エタノールを加充て粘質物を沈激させる。沈澱物を更に水に加温溶解し

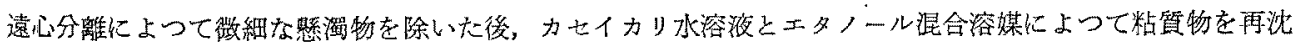
澱させる。沈激物を含水エタノールで洗浄後，エーテルで观理，真空乾燥して五酸化橉デシケータ中に保存 した。

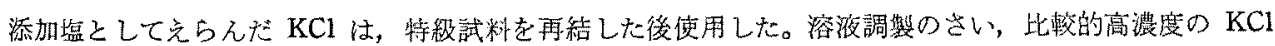
溶液に対しては普通の蒸溜水を，低濃度 $\mathrm{KCl}$ 溶液特よび純水に対しては長いシリカ管を通して注意深く再 溜した水を用いた。

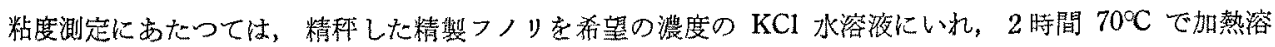
解させる。この液を直りに No. 4 のガラスフィルターを通して沪過し測定に供した。

* 本研究を Studies on Physico-Chemical Properties of Marine Products and Related Substances-XI とする。

** 京都大学農学部水産学教室 (Dept. Fish., Kyoto Univ.). 


\section{2. 粘 度 計}

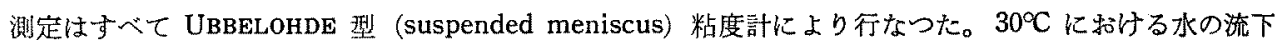
時間は 282.6 梨であつた。测定は $30 \pm 0.01^{\circ} \mathrm{C}$ に保つた恒温槽中で行なつた。本粘度計では粘度に対する 運動エネルギーの補正は無視できるほど小さい。速度勾配の影響は還元粘度の值がかなり高いことから十分 予想されるところであるが，ここでは考虑しないことにした。

\section{実験結果および考察}

\section{1. 還元粘度対濃度曲線}

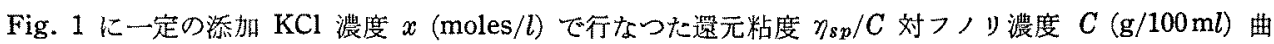
線を示す。Fig. 1 の曲線群の一般的傾向はこれまで多くの研究者によつて報告されている他の線状高分子 電解質のそれと全く相似である ${ }^{4,5)}$ 。寒天の場合と比較すると，二三の興味ある事柄がみいだされる。第一 に， $\eta_{s p} / C$ の值が寒天のそれに比较して著しく高いこと，第二に $\eta_{s p} / C$ の極大值が同じ $x$ の值でくらべた

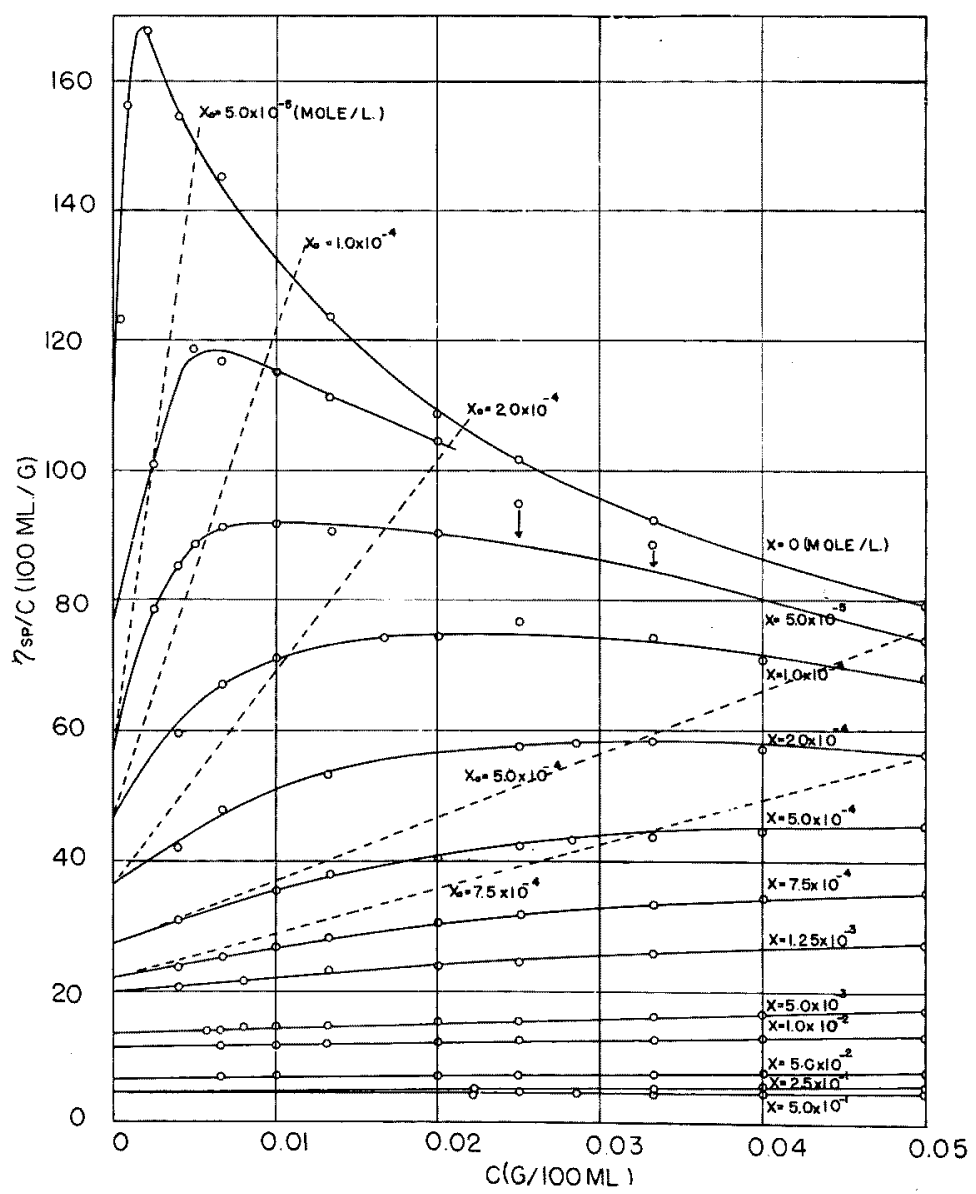

Fig. 1. Reduced viscosity curves of Funori in aqueous potassium chloride at different ionic strengths. $x$ denotes the concentration of added $\mathrm{KCl}$ in moles per liter. Broken lines refer to the calculated iso-ionic dilution curves. $x_{0}$ is the total ionic strength of the solution expressed in moles per liter. 
時，寒天に抽いて牥られるよりる更に低いCのの值にあらわれることである。これらの特幑は，寒天とフ，

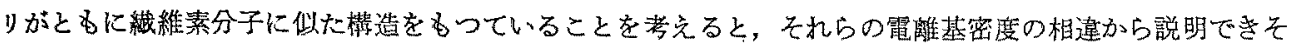
ろである。実際，本試料の硫酸基密度を硫酸重量法できぬ結果は $0.391\left(\mathrm{~mole} / \mathrm{C}_{6} \mathrm{H}_{10} \mathrm{O}_{5}\right)$ であり，市眅溏 フノリについて勝浦”が求めたカルボギンル基の密度は $0.045\left(\mathrm{~mole} / \mathrm{C}_{6} \mathrm{H}_{10} \mathrm{O}_{5}\right.$ ) であつて，寒天と此較して 䄪 5 倍（寒天は硫酸基，カルボキシル基あかせて $0.087\left(\mathrm{~mole} / \mathrm{C}_{6} \mathrm{H}_{10} \mathrm{O}_{5}\right)$ ) の電離基密度をるつているのであ る。この外，分子量の相違与考えなければならないである5が，測定を行なつていないので今の所何とるい 充な。

PALS および HERMANS" は NaCMC 和よびペクチン酸ソーダについて，向し溶液をその全イオン強度

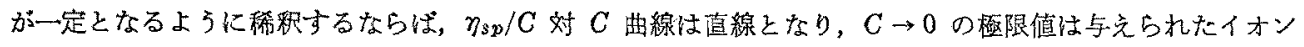
強度の溶液中の高分子の極限粘度を与えることを示した。この稀釈法を“iso-ionic dilution”とよんでい る。彼らによると溶液の全イオン強度 $x_{0}$ (moles $/ l$ ) は次式で表わされる：

$$
x_{0}=x+10 r m C \text {, }
$$

ここに，rは高分子塩 $1 \mathrm{~g}$ あたりの当量数， $m$ は高分子電解質 1 当量に対応する低分子篮のモル数である。 $m$ の物理的意義はきわめてあいまいであるが, 高分子電解質電荷が1価で添加低分子塩のそれが 1 価である 時は $m=1$ と考光られ易い。事夷 PALS 括よび HERMANS は NaCMC の食塩水溶液粘度について $m=1$

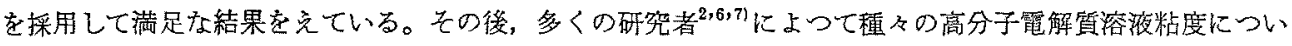
てこの稀釈法が研究されたが，ｍに１より小さい值を与えないと直線的な粘度曲線はえられなかつた。こ の原因注对1オンが高分子イオンに固定されて，有效な電荷在減少したためと洘方られている。

本実験仙 iso-ionic dilution によらず，一定の $x$ で $C$ をがる稀釉法を用いている。しかしながら， HERMANS の考えが正しいるのとすれば，Fig. 1 の曲線群から一定の $x_{0}$ に和讨る粘度曲線を作図すること ができる。い屯， $x_{0}$ 蚂よび $m$ に任意の值を与光 $r$ に既知の值 $\left(2.69 \times 10^{-3} \mathrm{eq} / \mathrm{g}\right)$ を用いると，(1) 式に したがつて $x$ を固定した粘度曲線上から $C$ が求末る。この操作を他の一定 $x$ の粘度曲楾に適用すると,

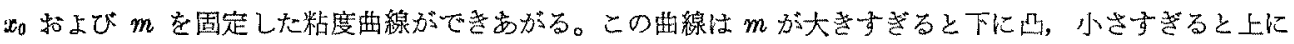
凸となる。このようにして，粘度曲線がらようど直線になるような $m$ の值を定めることができる。Fig. 1 に破線で示したのはこの方法によつて作图した粘度曲線である。本実駼に括りる より小さい。比較のために前䢞の寒天のデーダにこの方法を適用すると $m=0.60$ の值をえた。このこと から，電離基密度の大きいものほぞ $m$ が小さくなる傾向がうかがわれる。この傾向は，卞で桜田・伊勢

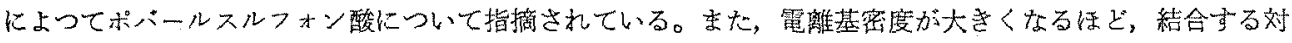
イオンの濃度が增大し高分子イオンの有效な電荷を隇少するとい5今井らの理論的結果多々一一致する。る つとも，桜田らのデータは主鎖が全く同一で電離基密度のみ異なる場合であるに対し，フノりと寒天のよ

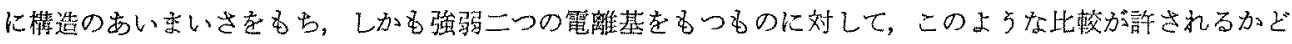
5 か子梌討老要导る。

\section{2. 極限粘度}

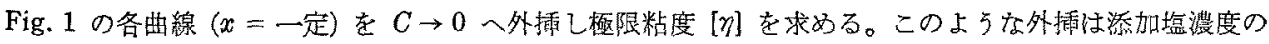

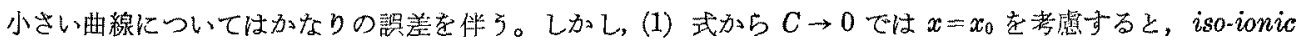

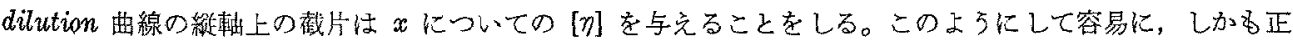
確に [ク] を外雨することができる。光られた極限粘度 [ク] 1 $1 \sqrt{x}$ に対してえがくと Fig. 2 のようにな

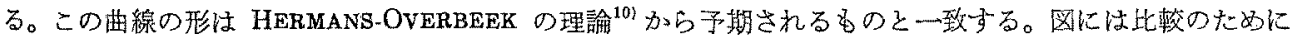

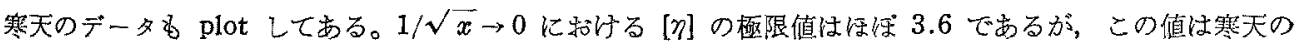

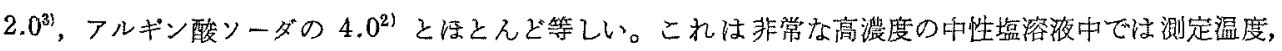

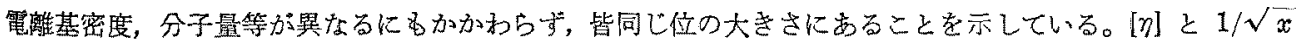
曲線の最初の直線部分の傾斜は，高分子塩の総電荷数と重合度に関係する量であるが，フノリの方が寒天上 


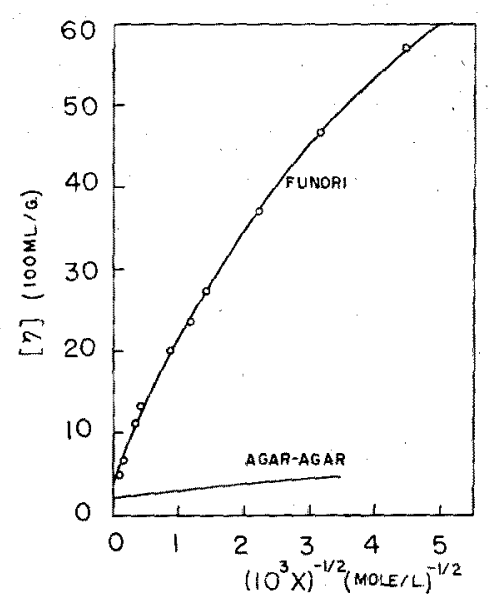

Fig. 2. Intrinsic viscosity plotted against the reciprocal root of ionic strength, $x$.

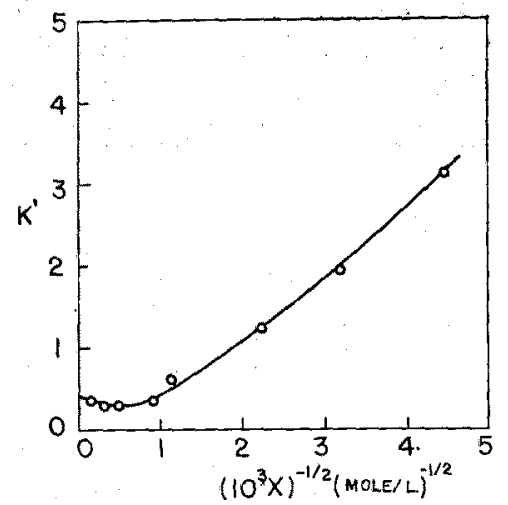

Fig. 3. The HUgGins slope constant $k^{\prime}$, plotted against the reciprocal root of ionic strength, $x$.

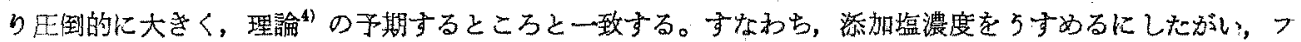
ノリ分子は寒天分子ょり引き延ばされるのである。

最後に，Fig. 1 の曲線の $C=0$ に甜ける傾科から求まる HugGINS の定数 $k^{\prime}$ を $1 / \sqrt{x}$ に対して完か

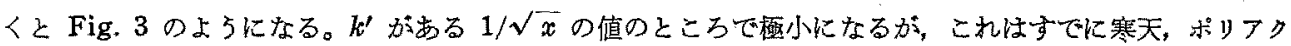
リル酸ソーダでみとめられたるのである。

\section{文献}

1) 勝浦塞久次・鈴木昭三郎：工化，59，1067 (1954).

2) H. Fujita, A. Kishimoto and K. NinomiYa: Memoirs Coll. Agr., Kyoto Univ., No. 76, 9 (1957).

3) 坂元道太郎・岸本 昭: 本誌，26，25 (1960).

4) D. T.F. PALS and J. J. Hermans: Rec. trav. chim., 71, 433 (1952).

5) 例穴保 H. FuJITA and T. HomMa: J. Polymer Sci., 15, 277 (1955).

6) H. Terayama and F. T. Wall: J. Polymer Sci., 16, 357 (1955).

7) H. Inagaki, H. SakuraI and T. Oda: Bull. Inst. Chem. Res., Kyoto Univ., 33, 257 (1955).

8) 桜田一郎・伊勢典夫：高分子化学，16，616 (1959); 一, 17, 146 (1960).

9）今井宜久.大沢文夫：物性論研究，No. 52, 42 (1952); - - No. 59, 99 (1953).

10) J. J. Hermans and J. Th. G. Overbeek: Rec. trav. chim., 67, 761 (1948). 